\title{
O ENSINO DA METODOLOGIA DE ASSISTENCIA DE ENFERMAGEM: RESPONSABILIDADE DA DISCIPLINA DE FUNDAMENTOS DE ENFERMAGEM
}

\author{
Leila Conceição Rosa dos Santos ** \\ Sandra Honorato da Silva*** \\ Maria Teresa Cicero Laganá *** \\ Thelma Leite de Araújo ***
}

SANTOS, L.C.R. dos; SILVA, S.H. da; LAGANA, M.T.C.; ARAÚJO, T.L. de O ensino da metodologia de assistência de enfermagem: responsabilidade da disciplina de Fundamentos de Enfermagem? Rev. Esc. Enf. USP, São Paulo, 21(1):75-88, abr. 1987.

As autoras, professoras de Fundamentos de Enfermagem, descrevem duas experiências de ensino da metodologia da assistência de enfermagem, em curso de graduação, para as quais foram utilizados dois tipos diferentes de campo de prática; no primeiro, o pessoal de enfermagem não utilizava a metodologia de assistência de enfermagem $e$, no segundo, a utilização dessa metodologia estava implantada. Dessas experiências, duas foram as conclusões: $1^{\circ}-A$ atitude dos alunos, que atuaram no primeiro campo de prática mencionado, era pessimista: consideravam eles, que a adoção da metodologia da assistência de enfermagem só era possível como atividade didática, mas não como atividade prafissional; ao passo que a atitude dos alunos que praticaram em campo onde essa metodologia estava implantada foi posiva sobre a conveniência de sua adoção; $2^{\circ}$ - Os alumos de Fundamentos de Enfermagem, devido à falta de conhecimento de patologia, não estão ainda preparados para identificar os problemas de enfermagem e propor soluções.

As autoras apresentam proposta sobre a gradação do ensino de metodologia da assistência de enfermagem no decorrer do curso, a fim de torná-lo mais efetivo.

UNITERMOS: Assistência de enfermagem. Processo de enfermagem. Fundamentos de Enfermagem.

\section{INTRODUÇĀO}

$\mathrm{Na}$ tentativa de descrever duas situações do ensino da metodologia de assistência de enfermagem, cabe ressaltar a recente promulgação da Lei $\mathrm{n}^{9} 7498 / 86$, publicada no D. O. em 26-06-86, dispondo sobre a regulamentação do exercício da enfermagem. Os artigos $4^{\circ}$ e $o 11$ parágrafo $\mathrm{I}$, item $j$, determinam privativamente aos enfermeiros a competência da prescrição da assistência de enfermagem, estando, portanto, conquistado um direito pelo qual há muito esperavamos. Em decorrência desta conquista aumentam a responsabilidade e o compromisso que as escolas

* Trabalho apresentado no XXXVIII CBEn e ganhador do $2 \circ$ lugar do Prêmio WANDA HORTA.

** Enfermeira. Auxiliar de Ensino do Departamento de Enfermagem Médico-Cirúrgica da Escola de Enfermagem da USP-Disciplina Fundamentos de Enfermagem I.

*** Enfermeira. Professor Assistente do Departamento de Enfermagem Médico-Cirúrgica da Escola de Enfermagem da USP-Disciplina Fundamentos de Enfermagem I. 
de graduação em enfermagem terão diante do aluno, no sentido de capacitá-lo para planejar e implementar a assistência de enfermagem, habilitando-o a ser um profissional que desempenhe com eficiência seu papel $e$, consequientemente, assegure ao ser humano a garantia de ser atendido em suas necessidades básicas.

A enfermagem sempre esteve preocupada em desenvolver uma metodologia de assistência que objetivasse aprimorar a qualidade do cuidado prestado ao paciente. Esta metodologia tem recebido diferentes denomi naçōes, como: plano de cuidados, processo de enfermagem, sistemática de assistência ou metodologia de assistência, sendo este último sido adotado no presente trabalho.

HUNDERSON ${ }^{6}$, fazendo o estudo da origem do Processo de En. fermagem, cita o livro publicado por Jesen (1929), onde esta descreve um método que começava a ser empregado na Escola de Enfermagem da Universidade de Yale (EUA). Este procura analisar o porquê do paciênte estar internado, o que este iria fazer quando voltasse para casa e em que a enfermeira poderia ajudá-lo.

Em nosso meio, a metodologia do processo de enfermagem, desenvolvida por Wanda Horta, baseada na teoria das necessidades humanas básicas, tem influenciado não só as diretrizes do ensino como as da prática de enfermagem. ${ }^{5}$ A própria Dra. Wanda foi grande incentivadora da continuidade dos estudos sobre o processo de enfermagem, com o acréscimo por ela proposto, acreditando que somente estudos mais profundos sobre sua aplicação, na prática, concorreriam para seu aperfeiçoamento, a elevação da qualidade da assistência prestada e o nivel profissional do enfermeiro. Data de 1963 a primeira experiência didática na Escola de Enfermagem da USP sobre a utilização do plano de cuidados como requisito básico para o estágio prático, parte do planejamento global de atividades do aluno. ${ }^{7}$ Desde então várias experiências têm sido relatadas a respeito de estudos realizados para implantação da metodo. logia de assistência, em diferentes instituições de saúde, e têm surgido propostas e estratégias de ensino visando a introdução do assunto nos cursos de graduação. 1, 3, 4, 8, 10, 12, 13, 14, 15, 16.

\section{CARACTERIZAÇĀO DA DISCIPLINA}

A disciplina Fundamentos de Enfermagem I é ministrada, na Escola de Enfermagem da USP, no $3^{\circ}$ semestre do curso de graduação; tem como pré-requisitos as disciplinas do tronco profissional comum e Intradução à Enfermagem. Sua carga horária total é de 330 horas, distribuídas em 180 horas teóricas e 150 horas de prátíca de campo. Os objetivos da disciplina são iniciar o aluno:

- no processo de ajuda ao individuo hospitalizado com necessidades humanas básicas afetadas;

- no processo de desenvolvimento da responsabilidade profissional; na execução dos procedimentos básicos de enfermagem, com aplicação de princípios científicos; 
- na utilização da metodologia de assistência para o planejamento e execução dos cuidados de enfermagem individualizados aos pacientes

A partir destes objetivos do plano de ensino, desenvolvemos o conteúdo programático da disciplina com alunos que, habitualmente, p3ssam pela sua primeira experiência com o adulto doente hospitalizado. Embora assim especificados, os objetivos da disciplina convergem para seu item último, por acreditarmos que, através da metodologia de assistência, introduzimos o educando na assistência de enfermagem de mareira compromissada, levando em conta o desenvolvimento das habilida. des psicomotoras dos procedimentos, sem, no entanto, perder de vista as áreas e cognitiva do mesmo.

\section{RELATO DAS EXPERIENCIAS DE ENSINO}

$O$ ensino da metodologia de assistência, uma abordagem de orientação para os problemas do paciente, foi introduzido na disciplina Fundamentos de Enfermagem I a partir de 1977, conforme relato de PAULA et alii ${ }^{14}$ Nos anos subsequientes essa proposta foi colocada em prática, sofrendo apenas algumas modificações eventuais, como a alteração da relação númerica professor-aluno, que nos últimos 5 anos foi de 1 para 12 , e estabelecimento de uma carga horária prática de 150 horas. Em 1982 foi modificado o histórico de enfermagem anteriormente adotado (Histórico de Enfermagem III, HORTA ${ }^{9}$ ) e as docentes passaram a trabalhar com um modelo adaptado, mantendo-os impressos: mapa de problemas e evolução do estado do paciente e prescrição de enfermagem (anexo 1). O tempo destinado à aprendizagem teórica da metodologia de assistência era de aproximadamente 20 horas-aulas. Nesse período os alunos aprendiam conceitos sobre a metodologia de assistência, suas fases, utilização e vantagens, tomavam conhecimento dos impressos adotados pela disciplina e aprendiam a utilizá-lo. A prática de campo era feita em unidade de internação que atendiam aos objetivos referentes aos procedimentos básicos de enfermagem e ao desenvolvimento de habilidades psicomotoras, mas que não utilizavam a metodologia de assistência de enfermagem como condições essencial para a prestação de asistência. Os alunos, no campo de prática elaboravam histórico de enfermagem (entrevista e exame físico), relativamente, no impresso específico, os problemas de enfermagem identificados e as ações propostas, para solucioná-los, registravam a evolução do estado do paciente e prescreviam cuidados que eram prestados por eles próprios. O enfoque da metodologia de assistência era eminentemente didático, servindo de guia para o trabalho do aluno, mas desvinculado da prestação de assistência feita pela equipe de enfermagem da unidade de internação.

Com a utilização dessa proposta didática foram alcançados os seguintes resultados: o aluno era iniciado na aplicação do método cientifico para a resolução de problemas, tomava conhecimento teórico sobre a metodologia de assistência e praticava, naquilo que lhe competia, as fases adotadas; prestava cuidados de enfermagem de forma sistematizada e o docente contava com um importante instrumento para orientação, supervisão e avaliação do discente. Entretanto era verificado que 
não havia incorporação, no espírito do aluno, da filosofia da metodologia de assistência de enfermagem como condição para a prestação de assistência na vida profissional; a atitude dos alunos era pessimista em relação à mesma, pois consideravam ser essa prática, possivel apenas como atividade didática, mas impossível como atividade profissional. Estudo realizado por $\mathrm{KOCH} \& \mathrm{OKA}^{12}$, corrobora o pressuposto de que uma das dificuldades encontradas pelo aluno na aplicação da metodologia está relacionada à falta de participação dos membros da equipe de enfermagem na sua elaboração e execução.

Avaliando estes resultados refletindo sobre os objetivos de ensino propostos, deparamo-nos com uma das principais dicotomias de enfermagem, ou seja, o ensino $\times$ a prática profissional. Surgiram, por isso dúvidas que apresentamos a seguir, a fim de podermos focalizar a metodologia de assistência de enfermagem no processo ensino-aprendizagem:

"Qual é o perfil do enfermeiro, na sociedade, que o aluno de Fundamentos de EnfermagemI deve incorporar?"

"Que obstáculos o aluno de Fundamentos de Enfermagem I enfrenta no campo, na implementação da metodologia de assistência?"

Estes dois pontos geraram discussões entre os docentes da disciplina, acerca de que maneira deveria ser discutida sua estratégia de ensino, tendo, sido delineados alguns princípios filosóficos para a programação das experiências teórico-práticas a saber:

- Fundamentos de Enfermagem I não se propõe a desenvolver apenas o papel instrumental, nem pretende formar um produto final;

- Fundamentos de Enfermagem I deve dar mais ênfase à aquisição de conhecimentos e principios, do que a procedimentos;

- Fundamentos de Enfermagem I deve despertar no educando o sentimento de responsabilidade pelo compromisso assistencial;

- O compromisso assistencial deve ser traduzido pela adoção de metódologia de assistência como a linha de Fundamentos de Enfermagem I, por envolver aspectos comportamentais e instrumentais do aluno e, portanto, o atendimento global ao homem.

Os docentes da disciplina Fundamentos de Enfermagem I decidiram, então, em 1986, modificar o ensino da prática da metodologia de assistência, adotando, como campos de estágio, unidades de internação onde a metodologia de assistência fosse utilizada para o atendimento ao paciente, procurando, dessa forma, aliar a teoria à prática profissional. O programa teórico oferecido sofreu poucas modificações, sendo suprimidas, apenas, as aulas em que os alunos conheciam e manuseavam os impressos adotados pela disciplina, já que agora iriam utilizar os das unidades de internação.

Os alunos foram distribuídos em 8 campos de prática e a relação númerica professor-aluno passou a 1 para 8 ; ficavam responsáveis pela assistência de 1 ou 2 pacientes, procurando seguir os itens prescritos 
pela enfermeira da unidade. Depois de um periodo inicial de duas semanas, durante o qual os alunos tomavam conhecimento dos históricos de enfermagem dos pacientes dos quais cuidavam e das respectivas prescriçōes de enfermagem, foram orientados em como elaborar históricos, avaliar as necessidades básicas do paciente, bem como a assistência de enfermagem a ser prestada, para realizar a evolução e a prescrição de enfermagem. Na tentativas de execução dessas atividades alguns fatos foram observados: o aluno de enfermagem tinha condições para elaborar o histórico, mas faltava-lhe conhecimento teórico para realizar um exame físico completo; além disso, a falta de conhecimento dificultava o levantamento dos problemas do paciente e a determinação das ações de enfermagem adequadas ao seu atendimento; conhecimentos prévios de fisiologia, anatomia, farmacologia, entre outros, eram desvinculados da patologia e da sua aplicação na assistência; a esses problemas acrescentava-se a necessidade de o aluno adquirir habilidade psicomotora na execução dos procedimentos. Os resultados observados dessa experiência foram: o aluno percebeu, de forma positiva, a imagem do profissional de campo; passou a considerar a metodologia de assistência de enfermagem como condição essencial para a prestação de assistência, pois não conseguia cuidar do paciente sem ter como guia a prescrição de enfermagem. Em contrapartida, foi verificado que o aluno de Fundamentos de Enfermagem I näo tem preparo científico suficiente para realizar um exame físi co completo, identificar alterações e problemas, elaborar evoluções e prescriçōes de enfermagem que possam servir como guia para a assistência prestada por toda equipe de enfermagem. O curto periodo de prática, aliado à falta de conhecimento e de habilidade, e a relação númerica professor-aluno são fatores importante que impedem esse aluno de assumir, de fato, a responsabilidade do histórico completo, da evolução e da prescrição de enfermagem dos pacientes sob seus cuidados.

As duas experiências de ensino relatadas e a relevância que a metodologia de assistência de enfermagem assume, hoje, levaram-nos a concluir:

"Atribuir ao aluno de Fundamentos de Enfermagem I a responsa. bilidade de avaliar, pacientes e determinar o conteúdo das prescrições de enfermagem seria negar a necessidade do conhecimento sobre a assistência de enfermagem em toda a sua amplitude".

E importante salientar que esta constatação pode ser feita justamente por termos buscado campos de prática com a metodologia de assistência efetivamente implantada, o que nos permitiu vivenciar a real natureza de sua operacionalização. Em conseqüência, é substancialmente diferente realizar evolução prescrições de enfermagem apenas como atividade didática e fazer o mesmo como prerrogativa de orientação da equipe de enfermagem, tarefa de alta importância e complexidade para a assistência ao paciente propriamente dita. Além disso, conforme TYLER 16 "a aprendizagem ocorre através do comportamento ativo do estudante: este aprende o que ele mesmo faz, o que faz o professor". Tal princípio re. futa a possibilidade do docente responsabilizar-se pela evolução e prescrição da enfermagem com o aluno, objetivando seu aprendizado; por 
outro lado, para que um comportamento ativo se efetive, são exigidos comportamentos prévios. Por isso, "Deixar que o ensino da metodologia de assistência ocorra circunstancialmente em apenas algumas etapas ao longo do curso de graduação é não assumir a responsabilidade da ga rantia do seu aprendizado".

\section{PRESSUPOSTOS PARA VIABILIZAR O ENSINO DA METODOLOGIA DE ASSISTÊNCIA NA DISCIPLINA E NO CURSO DE GRADUAÇÃO}

A metodologia da assistência constitui, em essência, o retornar do enfermeiro à sua função primordial de coordenador da assistência de enfermagem, função que se tem descaracterizado, ao longo do exercício profissional, pela sobrecarga de tarefas burocráticas impostas pelas instituiçôes, as quais provoca seu distanciamento da equipe de enfermagem e d $\rho$ paciente. Assim, o aprendizado da metodologia de assistência assume importância fundamental e é responsabilidade das escolas de graduação oferecer ao aluno os meios necessários para que a torne nessa função competente.

Com o advento da nova lei do exercício profissional, a prescrição de enfermagem assume papel de destaque, o que muda o enfoque dado ao ensino da metodologia. Se, até o presente não houve grande preocupação no sentido de o aluno, no final do curso de graduação, demonstrar competência para prescrever a assistência de enfermagem, fica agora patenteada a necessidade de seu melhor preparo para que o dispositivo legal seja viabilizado.

"A formação de hábitos é uma meta da educação. Assim também de idéias e de valores, sejam elementares ou transcedentais: a escola os inocula, os radica, os seleciona, os apura, por meio de vivência é o fazeı contínuo, é por ela que construímos a existência. Valores ideais, hábitos, configuram o caráter: ou este é vivido de fato, ou se dilui na beleza abstrata das palavras", KELLY ${ }^{11}$.

Cabe portanto a nós, educadores, criar condições para que a vivência de coordenar a assistência de enfermagem seja experimentada, aprendida e, conseqüentemente, incorporada ao conhecimento do aluno como valor maior para o desempenho da função de enfermeiro.

Diante do exposto passaremos a algumas propostas que, se efetivadas, favorecerão o real aprendizado da metodologia de assistência de enfermagem, enfatizando, primeiramente, os pressupostos educacionais e filosóficos que adotamos.

Pressupostas relacionados ao processo ensino-aprendizagem.

- O ensino da metodologia de assistência de enfermagem pretende abranger o desenvolvimento das três áreas comportamentais: a cogni. tiva, a psicomotora e a afetiva.

- O aprendizado da metodologia de assistência de enfermagem é um aprendizado de alta coplexidade, devendo, ser levada em conta sua gradação e continuidade ao longo do curso de graduação. 
- A gradação que o ensino da metodologia de assistência de enfermagem deve assumir pressupõe a adoção de um marco conceitual pelo corpo docente, que desenvolveria o ensino durante todo o curso, de maneira homogênea.

- A aprendizagem é um acontecimento que ocorre sob determinadas condições, ou seja, o docente precisa prever e organizar todas as condições necessárias para que ela ocorra.

- Em qualquer situação, o processo ensino-aprendizagem deve caminhar num crescente de complexidade de experiências proporcionadas ao educando $\mathrm{e}$,

- A verificação da fixação da aprendizagem é uma etapa indis. pensável quando se pretende assegurar um perfil adequado do educando ao final do curso.

Pressupostas relacionados à disciplina Fundamentos de Enfermagem 1 .

- A disciplina direciona seu conteúdo teórico para o atendimento das necessidades básicas do ser humano.

- A disciplina deve prever não só o ensino da metodologia de assistência de enfermagem, como também a aquisiçắo dos conhecimentos $\mathrm{e}$ habilidades necessárias à implementação dos procedimentos de enfermagem;

- O conteúdo programático da disciplina, prevê o ensino de sinais e sintomas das doenças e a respectiva assistência de enfermagem, mesmo não sendo as patologias o enfoque determinante do ensino.

- O educando vivencia, na disciplina Fundamentos de Enfermagem I, seus primeiros contatos com a profissão propriamente dita, devendo, portanto, dispor de um periodo de adaptação, principalmente ao ambiente hospitalar, que é via de regra, seu campo de prática e, onde são iniciadas suas atividades.

- A relação numérica professor-aluno de 1 para 8 , geralmente adotada não permite que o princípio de ensino individualizado seja seguido nessa fase inicial, devendo o docente prever estratégias que atendam os objetivos da disciplina e que, ao mesmo tempo, minimizem a falta de assistência individual que o professor deve proporcionar ao aluno.

- Deve haver coerência entre o que os docentes da disciplina ensinam, teoricamente, e a prática do aluno no hospital. Em função disso os docentes devem selecionar campos que adotem a metodologia de assistência, como embasamento da abordagem e implementação da assistência de enfermagem.

\section{PROPOSTAS}

"As mudanças importantes no comportamento humano não são prozidas de um dia para o outro. Nenhuma experiência isolada de aprendizagem tem influência muito profunda sobre o educando. As modifica- 
çőes na maneira de pensar, nos hábitos fundamentais, nos grandes conceitos operantes, nas atitudes, nos interesses perduráveis desenvolvem-se vagarosamente. É pela cumulação de experiências educacionais que se conseguem produzir mudanças profundas no educando. E para que as experiência educacionais produzam esse efeito cumulativo elas devem ser organizadas de maneira a se reforçarem umas às outras". (18) O mesmo autor cita três critérios que devem ser atendidos na elaboração de um grupo bem organizado de experiências de aprendizagem: continuidade, seqüência, integração. "A continuidade refere-se à interação vertical dos elementos curriculares importantes. A seqüência relaciona-se com a continuidade, mas vai além dela. A seqüência, como critério, reitera o princípio que cada experiência sucessiva para da anterior, porém penetrando mais profundamente nos assuntos envolvidos. A integração, refere-se a relação horizontal das experiências. A organização destes critérios deve ser tal que ajude o estudante a obter uma visão cada vez mais unificada do seu comportamento em relação aos elementos tratados".

Em decorrência do raciocínio desenvolvido, seria natural pensarmos numa proposta de que seja instituida, na graduação, uma disciplina "metodologia de assistência", ministrada ao longo dos semestres de todo o curso. Tal proposta iria de encontro a alguns princípios do processo ensino-aprendizagem aqui exposto. Porém, analisando o caráter estanque que as disciplinas componentes do currículo assumem, correríamos o risco de separar a prática de enfermagem propriamente dita da metodologia de assistência. Parece-nos que o adequado seria propor que a metodologia de assistência de enfermagem constituísse uma unidade de ensino integrada no conteúdo das disciplinas do curriculo diretamente relacionadas à assistência de enfermagem. Tal proposta iria determinar a gradação que o ensino da mesma deveria assumir, em cada etapa, de maneira que, ao final do curso, o educando tivesse domínio de todos os componentes envolvidos na metodologia. Desta forma, o conhecimento e a vivência da metodologia desenvolver-se-iam paralelamente à assimilação do conhecimento da assistência de enfermagem em suas especialidades.

Para CARVALHO ${ }^{2}$, as duas características fundamentais da unidade de ensino são: promover a integração das experiências num todo significativo e selecioná-las dentro de um campo unitário.

A proposta de o ensino da metodologia ser ministrado sob forma de unidades de ensino prevê duplo aspecto de integração: docente assistencial e interdisciplinar.

A integração docente assistencial, refere-se às mudanças que os campos de prática deverão sofrer para que a vivência da metodologia de assistência possa ser concretizada. Consideramos ser fundamental que os departamentos de enfermagem de hospitais de ensino e universitários adotem em sua concepção filosófica, a metodologia assistencial como base para o desenvolvimento de suas atividades. Neste aspecto, docentes e enfermeiros assistenciais, em cada local, deverão estudar e propor metodologia compativel com suas crenças, levando em conta os recursos materiais e humanos envolvidos na assistência. 
Quanto à integração interdisciplinar cada escola deveria traçar o perfil do educando ao final do curso de graduação, no que tange à metodologia, e estabelecer as bases sobre as quais o ensino da mesma deverá ser desenvolvido. Posto isto, caberá ao corpo docente determinar a gradação que o ensino deve assumir em cada disciplina, compondo as unidades num crescente de experiências, cada vez mais abrangentes e profundas; dessa maneira, no final do curso, estaria garantida a competência do educando para propor ações de enfermagem que promovam assistência individualizada e direcionada aos reais problemas dos pacientes sob seus cuidados, assim como um guia que conduza com segurança todo o cuidado prestado pela equipe de enfermagem.

\section{CONSIDERAÇÖES FINAIS}

Uma vez que se estabeleça, nas escolas de graduação, um marco conceitual que norteie o ensino, tendo em vista o profissional que se pretende formar, ou seja, um enfermeiro que, no desenvolver de suas funções, tenha competência para determinar a assistência de enfermagem devida aos pacientes sob seus cuidados, muitos impasses poderiam ser resolvidos de forma bem sucedida, com melhores resultados do que os obtidos a partir de esforços individuais. A escola, enquanto formadora de recursos humanos, deve garantir o espaço profissional que os alunos terão, como enfermeiros, na equipe de saúde; para isso, deve estabelecer condições de acesso às informações científicas que favoreçam a expansão da consciência do aluno sobre o que significa ser enfermeiro na sociedade. Se se deseja formar uma consciência de grupo e, portanto, de classe, com a especificidađe de papéis que a caracterizem como tal, é na escola que, através do comportamento do indivíduo e da própria ação, em si mesma, dar-se-á aprendizagem individual segundo ROGERS 71, a partir do individual a consciência do grupo se expande, e estas, por sua vez, expande a dos indivíduos, num processo contínuo de ação-reflexão.

SANTOS, L.C.R. dos; SILVA, S.H. da; LAGANA, M.T.C.; ARAúJO, T.L. de The teaching of the nursing process to undergraduate students. Rev. Esc. Enf. USP, São Paulo, 21 (1):75-88, Apr. 1987.

The authors, instructors of Fundamentals of Nursing, describe two experiments in teaching nursing process, for which two different types of field of practice were used: the nursing personnel of the first hospital did not employ the nursing process in the care of their patients, but on the second haspital the utilization of this process had been adopted. Two outstanding expected results were obtained: 1. The group of students, who practised in the first hospital did not believe the utilization of the nursing process would be possible in professional practices; but the groups who had seen such process being used showed a totally different attitude and agreed about the convenience of the adaption of the nursing process by the hospitals; 2 . the students who are taking Fundamentals of Nursing are not get prepared to identify nursing prablems and to suggest solution, owing to their lack of knowledge of pathology.

The authors recommend the teaching of the nursing process gradually, througout the undergraduate course, in order to secure more effective results.

UNITERMS: Nursing care. Nursing process. Fundamentals of nursing. 


\section{REFERENCIAS BIBLIOGRÄFICAS}

1. CAR, M.C. et alii. Ensino da prescrição de enfermagem médico-cirúrgica da Escola de Enfermagem da Universidade te Sãn Paulo. Rev. Esc. Enf. USP. São Paulo, 19(2): 135-244, 1985.

2. Carvalho, I.M. o ensino por unidades didáticas. 3. end. Río de Janeiro, Fundação Getúlio Vargas, 1962. 227 p.

3. CASTellanos, B.E.P. Aplicação do processo de enfermagem ao cuidado do paciente na unidade de centro cirúrgico. Rev. Esc. Enf. USP, 12(3):170-86, 1978.

4. Cianciarullo, T.I. et alii. Prescrição de enfermagem: experiências de sua àplicação em hospital particular. Rev. Bras. Enf., Rio de Janeiro, 27(2):144-9, 1974.

5. GUTIERREZ, M.G.R. de. O processo de enfermagem: suas implicações no ensino e na prática. Rev. Paul. Fnf., São Paulo, 1(0):11-2, 1981.

6. HENDERSON, V. On nursing care plans and their history. Nurs. Outlook, New York, 21(6) :378-379, 1973.

7. HORTA, W.A. O histórico de enfermagem simplificado. Enf. Novas Dimens., São Paulo, $2(3): 131-8,1976$.

8. HORTA, W.A. O processo de enfermagem: fundamentação e aplicação. Enf. Novas Dimens., São Paulo, 1(1):10-6, 1975.

9. HORTA, W.A. et alii. Ensino do plano de cuidados em fundamentos de enfermagem. Rev. Bras. Enf., Rio de Janeiro, 20(4):249-63, 1967.

10. KAMIYAMA, Y. et alii. Ensino do processo de enfermagem em doenças transmissiveis: experiência de integração hospital-escola. Enf. Novas Dimens., São Paulo, 5(1):23-30, 1979.

11. KELLY, C. Escola nova para um temponovo. Rio de Janeiro, José Olímpio, 1973.188 p.

12. KOCH, R.M. \& OKA, L.N. Processo de enfermagem: avaliação feita pelos alunos do departamento de enfermagem da UCP. Rev. Bras. Enf., Brasília, 30(3):274-85, 1977.

13. LUCKESI, M.A.V. et alii. Aplicação do processo de enfermagem no Hospital Ana Nery. Rev. Bras. Enf., Brasilia, 31(2):141-56, 1978.

14. PAULA, N.S. et alii. Assistência de enfermagem sistematizada: experiência de aprendizado. Rev. Bras. Enf., Brasília, 37(2):65-71, 1984.

15. PAULA, N.S. et alii. Processo de enfermagem orientado para os problemas do paciente: iniciação de ensino em Fundamentos de Enfermagem. Rev. Bras, Enf., Brasillia, 31(1) :101-13, 1978.

16. RESENDE, L.B. et alii. Implantação de metodologia assistencial de enfermagem no IASERJ. Rev. Bras. Enf., Brasilia, 34(2):123-37, 1981.

17. ROGERS, C. et alii. Em busca de vida. São Paulo, Summus, 1983.189 p.

18. TYLeR, R.W. Princípios básicos de curriculo e ensino. Porto Alegre, Globo, 1974. $119 \mathrm{p}$.

Recebido para publicação em $1 / 9 / 86$

Aprovado para publicação em $27 / 04 / 87$ 


\section{ANEXO I}

UNIVERSIDADE DE SAO PAULO

ESCOLA DE ENFERMAGEM

DISCIPLINAS: FUNDAMENTOS DE ENFERMAGEM E ENFERMAGEM MADICO-CIRURGICA I

I. Identificação

\section{HISTÓRICO DE ENFERMAGEM}

Nome RG Quarto Leito

Idade Sexo Est. Civil Escolaridade

Tipo de cirurgia Data da cirurgia

I. Atendimento das necessidades básicas-padrões, hábitos, frequiência, horários, rituais.

- Habitação (localização, cômodos, água, esgoto, lixo, combustível, luz, animais, insetos, quintal, jardim, etc.).

- Sono e repouso

- Alimentação e hidratação

- Eliminações

- Cuidado corporal

- Composição familiar

- Sexualidade e reprodução

- Recreação

- Educação à Saúde (fumo, álcool, medicamentos, alergias, imuniza-

- exames médico e dentário periódicos).

III. Percepções e expectativas - internação planejada ou não, o que sabe sobre a doença e tratamento, experiências anteriores, o que o incomoda (preocupações, medos, problemas), no que a doença e a hospitalização afetou hábitos, profissão, etc., como e no que espera ser ajudado.

IV. Exame físico.

Condições gerais: expressão facial, nível de consciência, locomoção, pastura, vestuário, coloração da pele.

Sinais objetivos: peso, altura, perimetros, TPR, PA, PVC. 
Condiçäes dos segmentos: (limpeza, lesð̃es, prurido, secreção, cor, forma, temperatura, turgor, motricidade, sensibilidade, distribuição de pelos, próteses, deformidades ou ausência de segmentos, sondas, drenos e catéteres, condiçōes da rede venosa e dos músculos para injeção).

- Cabeça: couro cabeludo, face, orgãos dos sentidos, cavidade bucal.

- Pescoço

- Membros superiores

- Membros inferiores

- Tronco-ventral: tórax, abdômen e genitais.

- dorsal: tórax, lombo-sacro, regiẫo anal e nádegas.

\section{Quedxas}

V. Impressões do entrevistador sobre o paciente.

VI. Diados clínicos de interesse para a enfermagem.

Data:

Assinatura do Aluno: 
MAPA DE PROBLEMAS

Nome do paciente:

No Leito:

Data de internação:

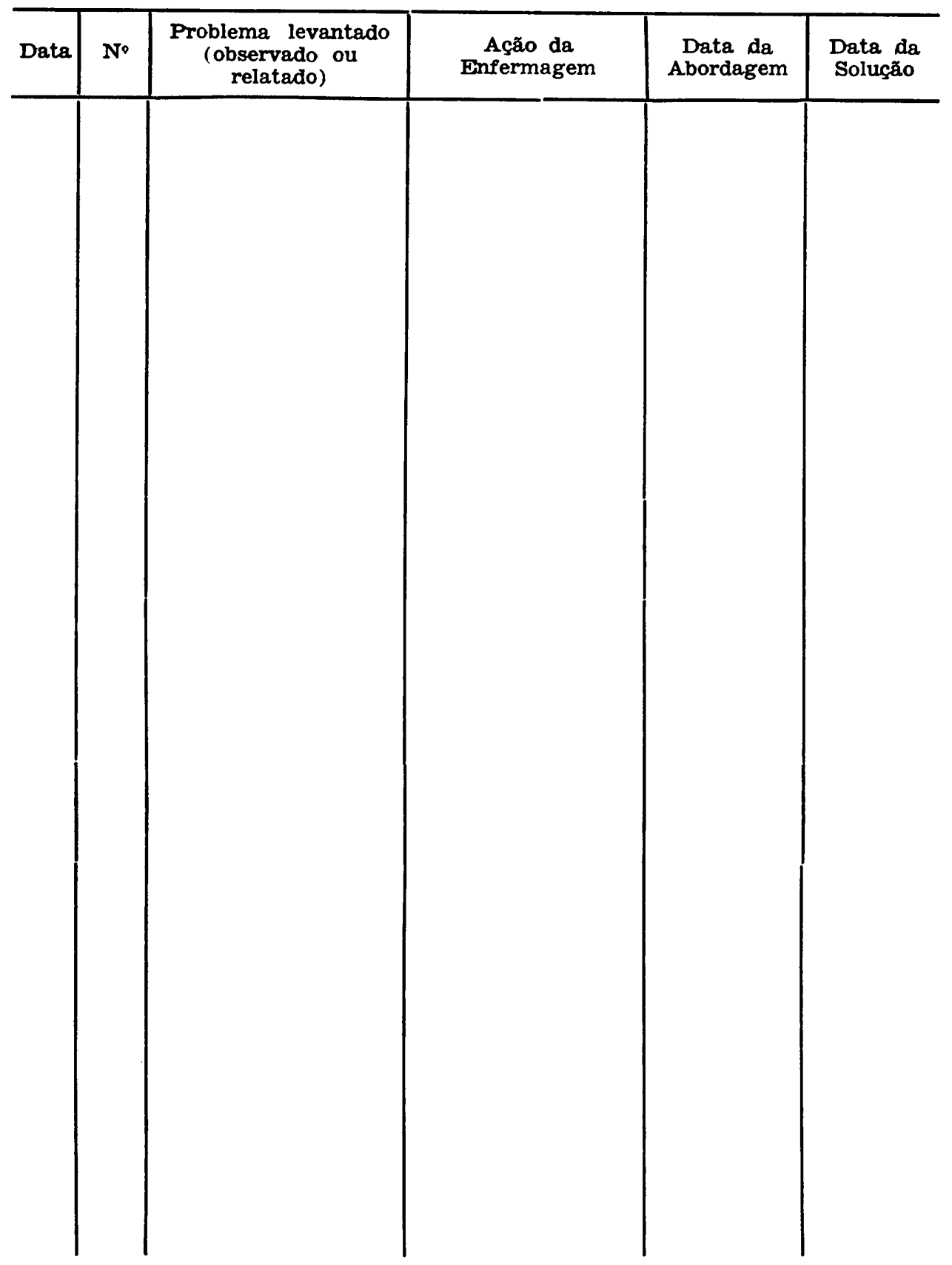

Rev. Esc. Enf. USP, São Paulo, 21(1):75-88, abr. 1987

87 


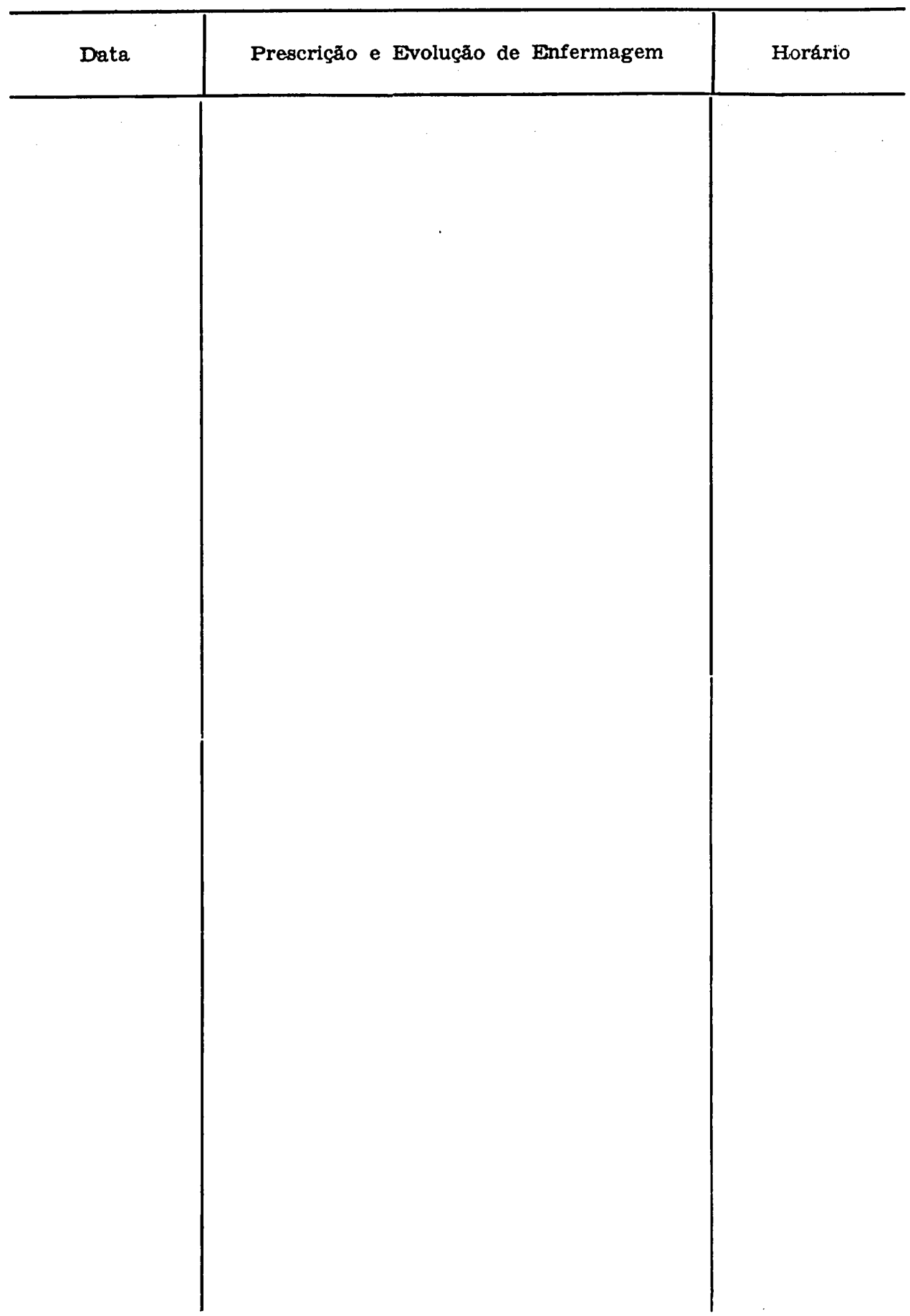

